\title{
Tragedy of Infertile Women of Hindu Society; Study of Middle Class Family of Kathmandu
}

\author{
Bishnu Prasad Dahal, Ph. D. \\ Anthropology, Patan Multiple Campus, Patan Dhoka, Tribhuvan University, Kathmandu, Nepal
}

\begin{abstract}
Infertility is perceived as only a medical problem in Nepalese society and there are no formal data of infertility. It is also a social problem in our society as cultural customs and perceived religious dictums may equate infertility with failure on a personal, interpersonal, or social level. It is imperative that people have adequate knowledge about infertility so couples can seek timely medical care and misconceptions can be rectified. In this paper the aim of this article is to assess the knowledge, perception and myths regarding infertility prevailing among middle class family of Kathmandu.
\end{abstract}

Ethnographic study was carried out in Kathmandu by interviewing a sample of 30 women who were accompanying the patients at three fertility centers in Kathmandu. They were interviewed in consultation with infertility specialists. The appropriate knowledge of infertility was found very poor amongst the participants. $40 \%$ of respondents identifiedthe infertility is a pathological and only $60 \%$ knew about the fertile period in women's cycle. Uses of emergency pills, late marriage, isolation of couples due to migrations etc are the causes of infertility were found during the study. Despite these, cultural beliefs, traditions, religious faith, myths etc are also found the important causes of infertility was found in study. Beliefs in cultural factors like evil forces and supernatural powers as a cause of infertility are also still prevalent especially amongst respondents though they are educated.Knowledge about infertility is limited in the population and a lot of misconceptions and myths are prevalent in the society. Alternative medicine is a popular option for seeking infertility treatment. The cultural and religious perspective about assisted reproductive technologies is unclear, which has resulted in its reduced acceptability.

Keywords: Knowledge, attitudes, perception, myths, infertility, infertility treatment,

\section{INTRODUCTION}

G lobally, motherhood is valorized as a milestone of Jadulthood for women (Riessman, 2002). In certain societies, an environment of pronatalism prevails, even with changing ideas around marriage, family forms and the economy and the relationships, social attributes, cultural patterns including produce and reproduce of offspring and values associated with it is to marry and reproduce, and any postponement in this phase of life is tolerated as a temporary delay rather than accepted as a permanent choice (Riessman, 2002). It is demonstrated that social interaction influences the regulation of fertility, and as such argues that reproductive matters ought to be analyzed in the context of the broader societal structure rather than fertility behavior only in which they occur (Agadjanian, 2001). It is found that children are constructed as socio-economic symbols of value for the family, and as symbols of "group continuity, strength, pride and honor" (Feldman-Savelsberg, 1994) for the kin group and for the community as a whole.

From research reports, it is found that 72 million women globally had self-reported as infertile, with a majority living in the Global South in 2009 (Brown and Heidrich, 2013). The statistics for infertility vary greatly from country to country and are only an estimate due to the sensitive nature of the condition, but Vayena et al (2002) suggest that, worldwide, it is approximately 13-24\%. The STDs most implicated include gonorrhea, Chlamydia and syphilis, which can cause damage through the scarring of fallopian tubes, and then lead to fetal loss through spontaneous abortion or stillborns (Ericksen and Brunette, 1996). Higher rates of infection are concentrated among young girls whose low immunological resistance can often result in permanent sterility (Richards, 2002).

The anthropological perspectives on demography mainly focus on the theme of causes and consequences of infertility(Hollos et al., 2009). It is focused on "What makes a woman infertile and why are such labels so significant socially?", "What are the meanings and consequences of infertility?" The tendencies of demographic explanations assume that women are hyper-fertile individuals "in need of reproductive regulation" (Upton, 2001), which consequently silences any discourse on infertility and renders invisible those individuals who are infertile, despite a demographic discourse on numbers that indicate an overall decline in the total fertility ratein any particular society, there is still an increasing extramarital fertility rate that has a direct correlation with the cultural construction of infertility and the significance placed on children (Upton, 2001). In Hindu orthodox society childbearing has been constructed as a key aspect of the female identity - so much so that bearing a child prior to marriage does not seem to create problems for the woman's social status, because of the value of reproduction.

The social and cultural aspects of infertility study infertile women's treatment seeking behavior; of infertility: personalistic and naturalistic. Personalistic explanations include "acts of people, spirits or witches" that cause infertility, while naturalistic explanations include biological causes of infertility, such as STIs or a low sperm count (Gerrits, 1997). In Kathmandu, it is not uncommon for personalistic and naturalistic explanations of infertility to be used in tandem, as mixing culture, traditions and biomedicine 
are not considered to be mutually exclusive. However, it is important to note that biomedical explanations and information about infertility is often largely inaccessible to poor and rural areas, particularly in developing countries (Guntupalli and Chenchelgudem, 2004).

For anthropology especially demographic anthropology, the causes of infertility and experiences of it should not only be understood from a medical standpoint, but are also influenced by socio-cultural contexts and they are socially constructed categories (Greil, McQuillan and Slauson-Blevins, 2011). In case of South India,the constructions of fertility and gender relationships ultimately shape the construction of infertility and the fertility satisfies social interests to extend lineage and insure inheritance through the female line (Neff, 1994). Several rituals conducted by the Nayars venerate and emphasize the importance of fertility, such as a puberty ceremony, a pre-puberty marriage ceremony and a formal marriage ceremony (Neff, 1994). The Nayar women are described as having a feminine power known as 'sakti', a procreative force that is understood to proliferate in other areas of society (Neff, 1994). Sakti is released for the benefit of the group when a woman is finally able to marry and bear children - without this step, her sakti is contained and accumulated and can bring on misfortune and disharmony for her kin group and society (Neff, 1994). When a woman is infertile among the Nayars, it is believed that it is a result of the wrath of the gods on the kin group and signifies curses that have befallen its members. Such beliefs mean that the infertile individual faces extreme vulnerability; she faces a stigmatized position as a barren woman, the loss of support from her kin group and social exclusion from her community (Neff, 1994).

Fertility is deified in two ways - through its capacity to ensure the continuation of a lineage, and to satisfy a man's greatest creation in Egyptian society - a child. As such, the consequences of infertility far outweigh the burden, embarrassment or fear of de-polluting healing rituals that infertile women go through to subscribe to Egyptian rituals, and to distance themselves from accusations of infertility. Infertility in Egypt,is understood to be caused by 'kabsa' when a polluted individual enters the room of a reproductively vulnerable woman (Inhorn, 1994). This "reproductively vulnerable woman" can be a woman who was recently circumcised or devirginized, or who has just delivered a child (Inhorn, 1994b). During this vulnerable state, a woman is isolated in a room for 40 days and is meant to be separated from contact with "polluting substances", which can include blood (vegetable blood, menstrual blood), unwashed substances (semen, breastmilk, urine), death or wealth (Inhorn, 1994b).

Similarly, the infertile women faced the various problems from society, they experiences and they feel loneliness, desperation, deep sadness and bitterness; they also described experiences of abuse in their families or communities where they were shouted at, cursed at or outcast (Dyer et al., 2002).
Later on anthropologists, examined the issues of infertility through aanthropological demographic approach, and found the differing rates of two communities in Nigeria and demonstrate how the meanings and psycho-social experiences attached to infertility are shaped locally through lineage structure and community mechanisms. Women in Lopon had less serious consequences for infertility than their counterparts in Amikiri, owing to the matrilineal structure of their community and the presence of community structures that economically or socially involved and supported infertile women (Hollos et al., 2009). It is clear that the community mechanisms and family structures are crucial for mitigating the effects of stigma, and the negative experiences of infertile individuals.

In most of the society, fertility especially motherhood is constructed as a woman's crowning glory, the pinnacle of achievement: and that are all destined for and ultimately the only means of true fulfillment (Fernandes et al., 2006) inHindu orthodox society too and the female body identity is identity of womanhood and motherhood which creates a sense of failed purpose or body that translates to a failed identity for those women who can't bear children. The infertile identity creates a complex experience of stigma, particularly in poorer communities where the woman faces disempowerment or stigmatization because of her "barrenness, femaleness and poorness" (Nahar and Richters, 2011). It is found that women barrenness further complicates their position, as the husband's family can claim back the bride price previously paid for the wife with the expectation that she would bear children (Dierickx et al., 2018). Reclaiming the bride price not only brings on feelings of shame for the woman and her family, but also places her family in a precarious economic position if they have already spent it. Having failed to bear a child, the woman often encounters social stigma from her family or wider community, where she is denied a higher social status or ostracized to levels that may even reach divorce, banishment, economic isolation or accusations of witchcraft (Hollos et al., 2009).

Infertility is one of the major health problems worldwide, including Nepal. The average prevalence of infertility in developing countries is estimated to be around 6.9-9.3\% ( Boivin, et al., 2007). An increasing trend of infertility has been noticed recently in Nepal however, exact prevalence is still unknown.

Among the various male and female infertility factors, abnormal reproductive tract, quality of sperm and embryo, abnormalities in the implantation process and other conditions including immunological factors are common. Similarly, lifestyle factors of infertility are sedentary lifestyle, heavy use of alcohol, smoking, late marriage, miscarriages and frequent abortion. Particularly in Nepal, millions of young fertile groups have migrated for job and they are coming back home after long gap and this may have reduced the fertility (Subedi et al., 2016). Some time, the migrant come to visit home and 
they might carry sexual transmitted diseases and this may have caused infertility.

Infertility is a universal phenomenon. Infertility has been described as 'the diminished or absent ability to conceive or produce an offspring' (WHO, 2006). The statistics for infertility vary greatly from country to country and are only an estimate due to the sensitive nature of the condition, but Vayena et al (2002) suggest that, worldwide, it is approximately $13-24 \%$. This difficulty is usually defined as taking longer than one year to conceive. In South Asia, about $4-10 \%$ of couples are affected by infertility, which appears to be a conservative figure suggesting those seeking treatment rather than those unable to conceive (WHO, 1991). It is found from the most research literature that the causes of infertility as a multidimensional health issue beyond genetic or biological problems related to the fallopian tubes, the ovaries and the endometrial including other reproductive health matter, but it is also a consequence of modern lifestyles and consumption patterns (alcohol, smoking), the higher average age of marriage, career and family-related stresses, and even environmental pollution and global warming.

The review of previous literature indicated that no study has discussed coping strategies specific to Nepalese individuals dealing with infertility. The qualitative data drawn from the key informants' interviews in this research will offer a rich account through the different groups interviewed: infertile individuals, religious leaders, community workers, health workers, traditional healers, and doctors. This approach also acts as a form of empowerment, allowing the voices of those included in this study to be heard, and highlighting their needs rather than silencing them - as tends to happen when broader national population policies are drawn up. It will focus on the perceptions of causes, the social meanings and the consequences of infertility, to contribute to the limited knowledge that exists in this area in the context of Nepalese people mostly of urban background. The objectives of this research article are to the growing attention for a social approach to the field of health psychology, one that prioritizes the emotional and interpersonal influences on people's behavior through anthropological approach. This paper examines the problems, issues related to infertility of women like socio-cultural, psycho-political, health, emotions, feelings, distress, etc. faced by women of middle class family in Kathmandu.

\section{METHODOLOGY}

This research was conducted in Kathmandu based fertility centers where the facilities for the infertile women were available for the treatment from August 2019 to February 2020.

During the course of this qualitative study semi-structured interviews were carried out among 30 married and educated middle-class women in Kathmandu from three fertility treatment centers. This information on maintaining confidentiality was provided to the participants both orally as well as through the information sheet. I have preserved the identity of my participants by using pseudonyms. I have changed the identification details of my participants such as their field of work and studies to preserve their anonymity.

Interviews were conducted in Nepali language with respondents of educated middle-class married infertile women. I preferred to interview those middle-class women who had at least high school passed (twelve class passed or attended).

The sample respondents have access to and knowledge about the reason behind the cause of infertility, degree or level of infertility problem, socio-cultural and psycho-political problems associated with infertility can understand easily.

\subsection{Socio- economic status of the Respondents;}

Respondents of age above 25 from middle-class backgrounds were selected, who were visited fertility centers for their treatment about infertility from three different fertility centers from Kathmandu- Kathmandu Fertility Center, Vatsalya IVF Nepal, World Fertility Services. Among the 30 respondents, 10 respondents from each fertility center were taken as sample survey. In this research both working and non working women were incorporated as respondents because it was very difficult to divide the respondents as in the various strata so as to difficult to gather information as per the research objectives.

The socio-economic status of all 30 respondents of three fertility centers, were found very small size both joint and nuclear family types in which married couples were infertile women. In this study, while defining, middle-class as those who have easily satisfied their basic needs and have more than the basic necessities of life (food, clothes, and shelter) such as a car/ motorcycle, mobile phone, laptop, air-conditioner, and fridge TV etc. accessories and home appliances with their satisfied job and easily sustained financial conditions. Middle class in Kathmandu is defined as originally inhabitants of Kathmandu; family of business, educated, entrepreneur, traders, employee, politicians, and families migrated to Kathmandu as neo- class from rural areas of Nepal. It is important to note that the new middle-class group shows similarities in ideas about gender relations and patriarchal values are common to the new middle-class (Belliappa, 2013).

The economic status of respondents have income ranges from the 10, 00,000 to above per annum. Because of their financial status, all of the respondents were able to access different reproductive health services including IVF service of treatment available in the markets to achieve their interests mainly associated with the baby conceiving for fertility in their infertility problem. Among 30 respondents, 25 were Hindu and 5 were Buddhist religion base.

\section{FINDINGS AND DISCUSSION}

Inpolygynous societies, when resources and goods differentially affect men's success in marrying and raising 
children, inheritance is strongly patrilineal or male biased cross-culturally, among traditional societies, women's ability to control resources, inherit property, and hold political office indeed have ecological correlates (Low, 2000). In case of studying infertile women among middle class educated women respondent it is clearly found that, all fertility associated with human fertility.

Table; 1 Distribution of respondent by caste and ethnicity.

\begin{tabular}{|c|c|c|c|}
\hline S.N. & Caste and Ethnicity & Respondent & Percentage \\
\hline 1 & Brahmin & 11 & 37 \\
\hline 2 & Chhetri & 9 & 30 \\
\hline 3 & Newar & 4 & 13 \\
\hline 4 & Tamang & 3 & 10 \\
\hline 5 & Rai & 2 & 7 \\
\hline 6 & Others & 1 & 3 \\
\hline & Total & 30 & 100 \\
\hline
\end{tabular}

(Source; Field survey, 2019-2020)

It found that psychological antecedents to female infertility would be caste specific and that a combination of sociocultural and ecological factors would affect various beliefs about gender. These field studies suggest that, in their resource allocation tasks, educated middle-class of Kathmandu significantly in favoring sons, as well as in attitudes toward female fidelity, culture-of-honor beliefs, and social distance measures. The overlap between educated middle-class of Kathmandu could be related to ecological changes in the Kathmandu and surrounding area. Their feelings of infertility, which originally emerged from their honor culture, have also spread to their attitude toward land holdings.

My research concluded that, infertility among the educated middle-class of Kathmandu has undergone changes in modern times: position and status of women are now being changed gradually once women were discriminated in terms of fertility but nowit is going to change due to the various reasons. Both husband and wife are treating equally by providing same or similar opportunities regarding education, and job opportunities with same investment according to their interest and capabilities.

While there are differences between South Asian cultures and communities, they are all firmly prenatal and patriarchal in nature. Great significance is placed on marriage, with arranged marriages being the norm for most people, regardless of social, mental or health status. Marriage and parenthood confer status and recognition for men as well as women. When a woman becomes a wife, she is accorded a higher status than a single woman, but when she becomes a mother her status then has prestige and security. This might, however, be the case only when she produces sons.

Women's identity comes from motherhood, and suggests that childless women are at risk of cruelty, rejection and divorce. Pressure can come, if not from the husband, from the family or wider community. This reaction, however, is less likely for those South Asians who have immigrated to Western countries (Culley et al, 2004). Nevertheless, insecurity in marriage is still a possibility if there is infertility.

These may relate to differences between religions groups in underlying socioeconomic characteristics, the particular tenets of a religious group which pass value judgments or prescribe appropriate actions on marriage, contraception and fertility, as well as the effect of minority group status on a community's integration in society and its impact on fertility preferences.

Table; 2 Distribution of respondent by religions.

\begin{tabular}{|c|c|c|c|}
\hline S.N. & Religions & Respondent & Percentage \\
\hline 1 & Hindu & 23 & 77 \\
\hline 2 & Buddhist & 5 & 17 \\
\hline 3 & Christians & 1 & 3 \\
\hline 4 & Muslim & 1 & 3 \\
\hline & Total & 30 & 100 \\
\hline
\end{tabular}

(Source; Field survey, 2019-2020)

Above table shows that, even if in any religion, there is a culture of against the infertility that are prevailing even though any kind of religious perception, values, attitudes, norms and traits. All regions are same in the context of infertility perception.For Hindus, the need to have a son or, failing that, a grandson, partly comes from the tradition of needing a son to perform the last religious rites at the death of the father: an important symbol of rebirth.

A child is considered a blessing, doubly so if it is a boy. Religious significance is linked to land and property tenure. Daughters often take a dowry from their birth family and become part of their husbands' families. Consequently, the birth of sons means that land, property and possessions can then stay within the family and thus provide a means of supporting parents in their old age. In this context, children, and particularly sons, are of vital importance to the survival and continuance of the family. The system of arranged marriages imposes a duty on families to ensure that a virginal bride is delivered to the future son-in-law; he, however, is not expected to be a virgin at their wedding. It is hoped that a pregnancy will soon follow the marriage, as that is seen as sealing the union and proving that the couple are healthy. The average age of marriage is less than in the West, although this trend is declining particularly among middle-class professionals, as a good education becomes more significant (Alesna-Llanto and Raymundo, 2005).

Women are taught that sexual intercourse is a duty, and contraception may not be used until after the birth of the first child. It also means that some marriages are unconsummated - a factor that accounts for a small but steady proportion of people seeking fertility treatment (Fisher et al, 2003). These seem to be mainly middle class professional women who arguably have more autonomy than their less educated sisters. This suggests that economic empowerment alone is not enough to liberate from sexual fear. 
There is a high incidence of polycystic ovary syndrome among South Asian women, compounded by an earlier onset and more severe symptoms than in other groups (Wijeyaratneet al, 2002). This may be genetic but it could be that South Asian women are diagnosed at an earlier age because they often want to start their families earlier than others. Other causes of infertility in women include fallopian tube damage, ovulatory disorders and endometriosis, but men account for nearly half of the causes of infertility in couples. In spite of this, Bharadwaj (2003) suggests that it is often the woman who takes responsibility for the lack of a pregnancy, while Nene et al (2005) assert that women cover for their sexually dysfunctional husbands in order to uphold the men's 'honour'.

Table; 3 Distribution of respondent by reason associated with infertility

\begin{tabular}{|c|c|c|c|}
\hline S.N. & $\begin{array}{c}\text { Reason associated with } \\
\text { Infertility }\end{array}$ & Respondent & Percentage \\
\hline 1 & General Health & 5 & 17 \\
\hline 2 & Reproductive Health & 7 & 23 \\
\hline 3 & Long Gap with Partners & 8 & 27 \\
\hline 4 & Myths and Religious & 10 & 33 \\
\hline & Total & 30 & 100 \\
\hline
\end{tabular}

(Source; Field survey, 2019-2020)

In developing countries, Butler (2003) suggests the cause of infertility is often reproductive tract damage as a result of sexually transmitted infections (STIs), notably gonorrhoea and chlamydia. However, in Britain the incidence of both of these conditions is rising fast although it could be that there is just better reporting (Shahmanesh et al, 2000). Where men are expected to get sexual experience prior to marriage from prostitutes, widows or deserted wives, there is an increased risk of infection.. Embarrassment could stem from various causes: lack of sexual knowledge, fear of not understanding the technical terminology, or general language difficulties and being made to look stupid. Many women who cannot conceive feel inferior and worthless, and language barriers can increase this anxiety.

This study explored women's and men's perceptionsof infertility and its causes, perception, treatmentseekingbehavior for infertility and the consequencesof childlessness in middle class family in Kathmandu.

The results shed lighton distinct gender-based differences in beliefsand behavior with regard to the causes of andresponses to infertility. Many of the explanationsgiven were partly or wholly inaccurate andthe forms of treatment sought would not havehelped to overcome the actual problems.In the case of women, except medical or pathological reason the leading cause ofinfertility was perceived to be related to evilspirits and the supernatural, affecting a womanthrough her menstruation. e.g. of a bhut(ghost) affectingthe woman's body. The traditional associationbetween women's bodies and evil spirits isbased on the belief that women are vulnerableprecisely because of their menstruation (Blanchet, 1984). Similartraditional beliefs in supernatural causes toexplain women's infertility, as well as the beliefthat it is God's will when traditional treatmentshave not worked, have been described in Egypt and South India ( Inhorn, 1994). In India,women also fault themselves but not their husbandsfor failing to produce children( Jindal and Gupta, 1989). .In the course of study it is found that, the men as partner of women were perceived as role in infertility, the causeswere attributed to psychosexual and physiologicalfactors in the man, some of which were todo with sexual excess or loss of sexual potency,which were linked with loss of fertility. A numberof physiological problems were mentionedwhich may signal infection (white discharge orchanges in seminal fluid) or were possiblesources of infection (unsafe induced abortion), haphazard use of emergency contraceptive pills. Yet untreated STDs and other reproductivetract infections were rarely perceived tobe the cause of infertility in women. Kathmandu is a place where society is found modern but the thinking associated with sexuality and fertility are found still conservative, with different systems of medicine beingused alongside each other. 'Modern' allopathicmedicine has not so much replaced indigenousmedicine as increased the therapeutic optionsavailable. In Kathmandu middle class family have betteraccess to hospitals, clinics and health careinformation than lower classes. In Kathmandu health serviceswere not designed to address easily available and reasonable in price. Furthermore, they are not well managed and facilities in government owned hospital are limited and is not easily access, patients have to wait for long periods,doctors are frequently absent and treatment isexpensive and often inappropriate.

Hence, Kathmandu middle class families utilize traditional healers and medicinesmost of the time. This includes seeking fortreatment for infertility; allopathic sources ofcare were mentioned very infrequently by therespondents in this study. In any case, at presentthere is no public health program that focuseson infertility in Kathmandu and few privateclinics provide infertility services. The few thatdo are very expensive.

Perceptions ofthe etiology of infertility in women lead them toseek treatment from practitioners who offer tocure illnesses due to supernatural causes. Herbalistsand healers of several kinds were the mostcommonly cited sources of treatment for womenin this study. A study in India similarly found thatinfertility was the most common gynecologicalcondition for which women visited faith healers (Parikh, et al, 1996).In this study, the belief in supernatural causes ofinfertility and the failure of traditional treatmentsto cure the problem led to the perception thatwomen's infertility was difficult or impossible totreat, and it was thus attributed to God's will.For men, remarriage was the most commonlymentioned solution, based on the belief thatwomen are the source of infertility. However,herbalists and traditional healers were alsocommonly cited as a treatment option for men, whether or 
not men commonly visit these practitionerscould not be determined from thisstudy, though one herbalist indicated that visitsto him from men for infertility treatment wererare. None of the respondents mentioned remarriageas an option for women, which may bedue to the difficulties faced by women who try toremarry, including stigmatization, lack of resourcesfor dowry, insecurity as to whether theywill be granted a divorce and the fear of trying tosurvive as a divorced woman.The consequences of infertility are particularlydifficult for women; childless women areperceived as inauspicious. Children are neededto fulfill important social and familial roles andobligations in Kathmandu, and families withoutchildren are considered failures. It is discouragingto observe that the women almost alwaysblamed themselves for infertility, even if theirhusbands were found to have a fertilityrelatedproblem. Yet religious teachings in the familyin Kathmandu instruct women to accept thesuperiority of men in all spheres of life; womenare taught that they are inferior to men by natureand should be blamed first if a fault of any sort isfound between a husband and a wife.

Because of the stigma attached to infertility,infertile women faced problems in both in theirin-laws' and their own parents' houses. Kathmandu is mostly dominated by Hindus and marriage among them is patrilocal and if they are in nuclear family they themselves decides what they want. It is found that if the family is extended, themother-in-law and sister-inlaw most often sidewith the husband, therefore aggravating situationsthat may lead to violence related to infertility. Some respondents in this study mentioned divorce,separation, suicide as a potential means of escapingviolence.

The Andra Pradesh study mentioned abovefound a very low risk of women being divorced bytheir husbands because of infertility (Unisa, 1999), In thisstudy, infertile women greatly feared abandonmentby their husbands, though the number ofcases in which this actually occurred in the middle class of Kathmandu could not be mentioned in this study.

The study shows that infertile men andwomen face many different types of socialstigma. For men, social stigmatization was not asdrastic as for women, but a clear lowering ofstatus was described in relation to childless men, with pressure on them to remarry in order tohave children. However, women clearly bear thegreatest burden of infertility in Kathmandu andsuffer serious emotional, social and socioeconomicconsequences. Health planners have neglected the issue ofinfertility in many developing countries, althoughit is a significant public health problem (Bergstrom, 1992).Community-based interventions for infertilityrequire an understanding of perceived causesof infertility and the reasons behind treatmentseekingbehavior from the community's perspective.

This study provides such an understanding; treatments sought were mostly in the indigenousdomain and unsuccessful, leading people tobelieve that infertility was difficult or impossible totreat. Few of the respondents related infertility tosexually transmitted diseases or other provencauses of infertility such as low sperm count. Hence, they attributed infertility to supernaturalcauses, fate and psychosexual problems. Successful programmes for dealing within fertility in Kathmandu need to include bothappropriate and effective sources of treatment atcommunity level, and communitybased interventionsto demystify the causes of infertility andto inform people of the actual causes, so that theyknow why infertility occurs in both men andwomen and where best to seek care.

\section{CONCLUSION}

The problem of infertility is not only the matter of health problem, but it is also associated with socio-cultural and psycho-religious problem which is a fairly common problem affecting approximatelyone-fifth of the population. It is found from the research that the knowledge about infertility is generally limitedamongst the participants, and the reason behind the infertility is assumed incapability of conceiving children is more somehow treated as the psycho-cultural and religious myths based problem rather than medical one only. The traditional cultural values and people's perception are more violent women in society. In fact, there are a lot of misconceptions, such as people's beliefs that IUCD andOCPs can cause infertility. People still believe in supernaturalpowers as a cause of infertility and seek treatmentfrom faith healers. Alternative medicine is also apopular option for couples in case they are not satisfiedwith allopathic medicine. Knowledge about treatmentoptions is also lacking and its cultural and religious perspectiveis unclear, which has resulted in reducedacceptability of assisted reproductive technologies.

It is found from the research that migration, long time insterility, haphazard use of emergency pills, improper use of use contraceptive devices etc also acting as infertility stages. But other factors cultural, social, psychological etc. are also most important for infertility too. If women is infertile in Hindu society especially in Kathmandu there is only the reason of women's incapability because male always do not want to show his incapability in patriarchy, Hindu orthodox society like study area.

\section{REFERENCES}

[1] Agadjanian,, V. 2001 Religion, Social Milieu, and the Contraceptive Revolution, Population Studies, 559(20), 135-148

[2] Alesna-Llanto and Raymundo, 2005 Contraceptive issues of youth and adolescents in developing countries: highlights from the Philippines and other Asian countries, Adolescent Medicine Clinics, 16(3):645-63.

[3] Belliappa, J.L. 2013 Gender, Class and Reflexive Modernity in India, Genders and Sexualities in the Social Sciences,MacMillion

[4] Bergstrom, S. 1992 Reproductive failure as a health priority in the third world: a review. East African Medical Journal, 69(4):174-80.

[5] Bharadwaj, A. 2003 why adoption is not an option in India: the visibility of infertility, the secrecy of donor insemination, and other cultural complexities. Social Science and Medicine 56:186780 . 
[6] Blanchet, T. 1984 Women, Pollution and Marginality: Meaning and Rituals of Birth in Rural Bangladesh, University Press, Dhaka.

[7] Boivin, J., Bunting, L., Collins, J. A., Nygren, K. G. 2007 International estimates of infertility prevalence and treatmentseeking: potential need and demand for infertility medical care, Human Reproduction, 22(6):1506-12.

[8] Butler, P.A. 2003 Progress in Reproductive Health Research No. 63. Geneva: World Health Organization

[9] Culley, L. Rapport, F., Katbamna, S., Johnson, M., Hudson, N 2004 A Study of the Provision of Infertility Services to South Asian Communities, De Montfort University, Leicester, Bedford

[10] Dierickx, P., Laake, L.W.V., Geijsen, N. 2018 Circadian clocks: from stem cells to tissue homeostasis and regeneration, EMBO. Rep. 19(1):18-28.

[11] Dyer, S. J., Abraham, N., Hoffman, M., Van der Spy, Z. M. 2002 Infertility in south Africa: women's reproductive health knowledge and treatment-seeking behaviour for involuntary childlessness. Hum Reprod., 17:1663-1668

[12] Ericksen, K.., Brunette, T. 1996 Patterns and predictors of infertility among African women: A cross-national survey of twenty-seven nations," Social Science \& Medicine, Elsevier, vol. 42(2), 209-220

[13] Feldman-Savelsberg, P. 1999 Plundered Kitchens, Empty Wombs: Threatened Reproduction and Identity in the Cameroon Grass fields. Ann Arbor: The University of Michigan Press.

[14] Fisher, J. A., Bowman, M., and Thomas, T. 2003 Issues for south Asian Indian patients surrounding sexuality, fertility, and childbirth in the US health care system. Journal of the American Board of Family Practice 16:151-5.

[15] Gerrits, T. 1997 Social and cultural aspects of infertility in Mozambique, Patient Education

[16] Guntupalli, A.M., Chenchelgudem, P. 2004 Perceptions, causes and consequences of infertility among the Chenchu tribe of India, Journal of Reproductive and Infant Psychology, 22,(4), 249-259

[17] Health in Bangladesh, Proceedings: Workshop on Implementation Women's Health Programs in the Community: The Bangladesh Experience BRAC, Dhaka

[18] Hollos, M.., Larsen, U., Obono, O., Whitehouse, B. 2009 The Problem of Infertility in High Fertility Populations: Meanings, Consequences and Coping Mechanisms in Two Nigerian Communities Social Science \& Medicine, 68, 2061-2068

[19] Inhorn, M. C. 1994 Quest for Conception: Gender, Infertility, and Egyptian Medical Tradition University of Pennsylvania Press, Philadelphia

[20] Jindal, U..N., Gupta, A. 1989 Social problems of infertile women in India, International Journal of Fertility. 34:30-33.
[21] Low, B.S. 2001 Why sex matters, Princeton University Press

[22] McQuillan, J., Greil, A., \&Shreffler, K. 2011 Pregnancy intentions among women who do not try: focusing on women who are okay either way. Journal of Maternal \& Child Health, 15, 178-187.

[23] Naab, F., Brown, ,R., Heidrich, S. 2013 Psychosocial health of infertile Ghanaian women and their infertility beliefs, Journal of Nursing Scholarship,45(2):132-40

[24] Nahar, P., Richters, A. 2011 Suffering of childless women in Bangladesh: the intersection of social identities of gender and class, Anthropology \& Medicine, 18:3, 327-338

[25] Neff, D. L. 1994 The social construction of infertility: the case of the matrilineal Nayars in New York.

[26] Nene, U. A., Coyaji, K., Apte, H. 2005 Infertility: a label of choice in the case of sexually dysfunctional couples. Patient Education and Counseling 59:234-9.

[27] Parikh, I., Taskar, V., Dharap, N. 1996 Gynaecological morbidity among women in a Bombay slum. (Unpublished)

[28] Richards, G. 2002. The Psychology of Psychology: A Historically Grounded Sketch, Staffordshire University12(1), 7-36

[29] Riessman, C. K. 2000 Stigma and everyday resistance practices: childless women in South India. Gender and Society. 14(1):111135.

[30] Shahmanesh, M., Gayed, S., Ashcroft, M. (et al) 2000 Geo mapping of Chlamydia and Gonorrhoea in Birmingham. Sexually Transmitted Infections 76:268-72.

[31] Subedi, S., Lamichhane, S., Chhetry, M. 2016 Study of Infertile Couples Attending a Teaching Hospital in Eastern Nepal, Journal of Nepal Medical Association, 55(203):22-25

[32] Unisa, S. 1999 Childlessness in Andhra Pradesh, India: treatmentseeking and consequences. Reproductive Health Matters 7(13):5464.

[33] Vayena, E., Rowe, P., Griffin, P. D. (eds) 2002 Current Practices and Controversies in Assisted Reproduction report of a WHO meeting. Geneva: World Health Organization

[34] Vayena, E., Rowe, P.., Griffin, P. D. (eds) 2002 Current Practices and Controversies in Assisted Reproduction: report of a WHO meeting. Geneva: World Health Organization

[35] WHO 1991 Infertility: A Tabulation of Available Data on Prevalence of Obstetrics. 46(2):181-87

[36] WHO 2003 En-gendering the Millennium Development Goals on Health, Geneva: World Health Organization

[37] Wijeyaratne, C. N., Balen, A.H., Barth J.H., Belchetz, P.E. 2002 Clinical manifestations and insulin resistance in polycystic ovary syndrome among south Asians and Caucasians: is there a difference? Clinical Endocrinology 57:343-50. 